\title{
LDL Cholesterol to HDL Cholesterol Ratio Measurement
}

National Cancer Institute

\section{Source}

National Cancer Institute. LDL Cholesterol to HDL Cholesterol Ratio Measurement. NCI

Thesaurus. Code C121182.

The determination of the ratio of LDL cholesterol compared to HDL cholesterol present in a sample. The measurement may be expressed as a ratio or percentage. 